\title{
Thyristor-Controlled AC Reactor Based Fault Current Limiter for Distribution Network Stability Enhancement
}

\author{
Hamid Radmanesh ${ }^{\dagger}$, S.H.Fathi* and G.B. Gharehpetian*
}

\begin{abstract}
Recently, various types of Solid State Fault Current Limiters (SSFCLs) have been proposed. These SSFCLs can improve the voltage quality, decrease the transmission losses, and also can enhance the distribution network stability but there are some practical problems with these FCLs. This paper proposes a modified FCL with focusing on the components optimization, efficiency improvement and reducing the cost. The suggested FCL uses a series AC reactor with controllable power electronic switches named Thyristor-Controlled AC Reactor (TCAR) which is connected in series with the feeder to limit the fault current and avoid fault current problems, which impairs overall distribution network reliability. The influence of TCAR on the fault current is analyzed using analytical, simulation and laboratory tests. The performance of the proposed TCAR in the simple distribution network is examined. The simulation and experimental results are in a good agreement with together and show the proper operation of the proposed TCAR during the normal and fault operation modes.
\end{abstract}

Keywords: Fault current limiter, Distribution network, Reliability, Protection, Power electronics

\section{Introduction}

Increase in electrical energy consumption and penetration of distributed generation increases the fault current level in distribution networks. The new faults current level should not exceed the maximum permissible short-circuit capacity of the protective equipment [1]. The costly solution to answer the fault current levels is continuous upgrading of the network's equipments [2]. Other solution for decreasing the fault current levels and avoiding the protective equipments upgrade is application of fault current limiters (FCLs) to limit fault current in permissible levels [2]. The FCLs application can improve the power quality, transient stability and reliability of the network. Also, the FCLs can mitigate the transformer inrush current even for capacitive loads [3-5]. The most popular power electronics based FCLs are bridge type FCLs (BFCLs) and are categorized into Solid-State FCLs (SSFCLs). The SSFCLs can be classified based on their reactors. Some FCLs use DC reactor on their structure and others use an $\mathrm{AC}$ reactor for limit the fault current. The DC reactor based SSFCLs have quick response, fast recovery and acceptable reliability. But these FCLs have power loss in normal operation and they cannot decrease the fault current to an acceptable level [6]. The first BFCL has been reported in [7] and later some improvements on it have

$\dagger$ Corresponding Author: Electrical Engineering Department, Aeronautical University of Science and Technology, Tehran, Iran. (Hamid.Radmanesh@aut.ac.ir)

* Electrical Engineering Department, Amirkabir University of Technology, Tehran, Iran. (\{fathi, grptian\}@aut.ac.ir)

Received: October 13, 2014; Accepted: March 2, 2016 been proposed in literatures. But, most of them still have problems. The basic structure was simple and does not require control system. However, this FCL can only limit the fault current for first three cycles and a bulky and expensive cooling system is needed to evacuate the significant conduction losses which arise in normal condition [7]. To overcome the BFCL problems, a controlled rectifier with a superconductive coil has been proposed in [8]. However, the proposed structure includes complicated control strategy. Then, a transformer-type DC reactor including a DC bias source, damping resistor and an IGBT switch in its secondary side is proposed [9-11]. This structure has less voltage drop in normal condition and a it has simple and reliable control strategy, but its switching overvoltage and power losses during the fault is not acceptable. One of the most common problems of the BFCLs refers to DC reactor equivalent resistance, which represents considerable losses [12]. Furthermore, in order to have proper FCL operation, this paper proposed a modified version of thyristor-controlled AC reactor (TCAR) FCL. The development of a simple and costeffective TCAR is presented that overcomes most of the drawbacks outlined previously. In fact, the newly proposed TCAR has negligible power loss in the normal operation, large impedance in the fault condition, quick response and fast recovery after fault removal. The proposed TCAR is simulated and practically tested in normal, and fault conditions. Experimental and simulation results are in good accordance with each other and confirm the high performance of the proposed TCAR.

The paper is organized as follows: in Section II, operating principles of the proposed TCAR in the 


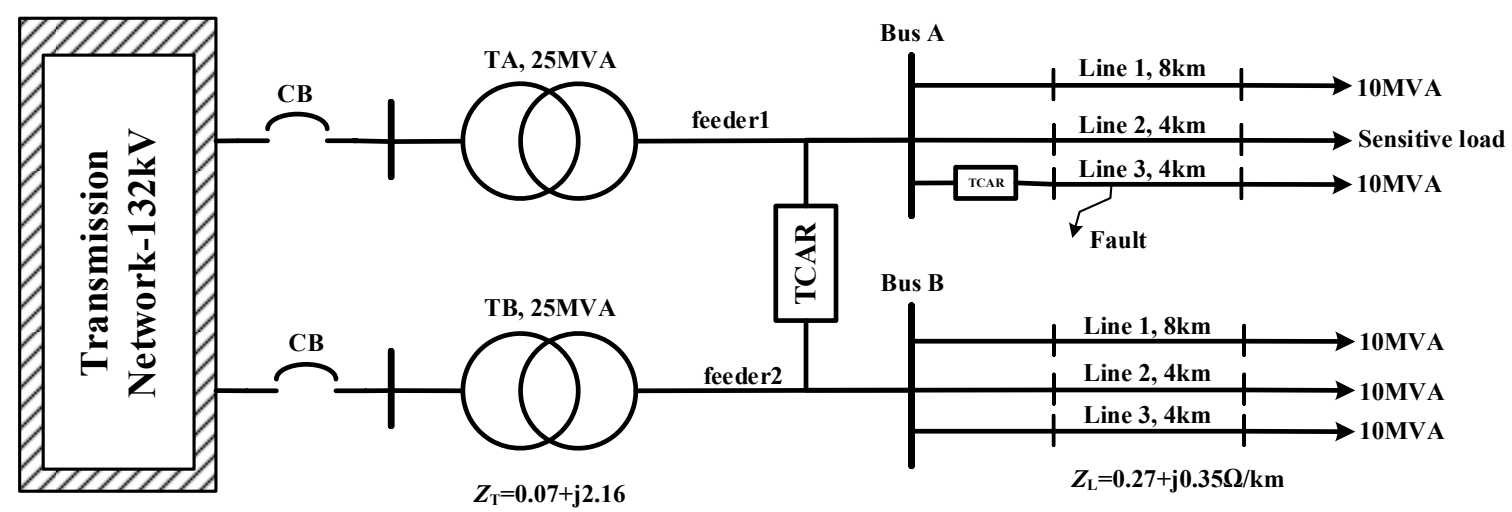

Fig. 1. Single line diagram of the distribution network

simplified distribution network are discussed. In ection III, the analytical study of the proposed TCAR is done. Performance of the single-phase TCAR is evaluated by simulation in MATLAB program in section IV. The experimental results are presented in section V. Finally, the main results are concluded.

\section{Electrical Network Modeling}

Fig. 1 shows single line diagram of the distribution network where TCAR is connected in series with the feeder1 to control and limit the fault current. Also, the TCAR is connected as a bus tie position with nominal rate of 25 MVA. This distribution system includes two distribution buses where each bus has 30MVA electrical load. These loads are connected to the transmission network via 25MVA power transformer.

In addition, these two buses are connected together via proposed TCAR with 25MVA nominal rate. The TCAR topology is shown in Fig. 2.

The proposed FCL includes two anti-parallel thyristors, a series AC reactor $\left(L_{\mathrm{d}}\right)$ and a metal oxide varistor (MOV) in parallel with the switches. During normal operation

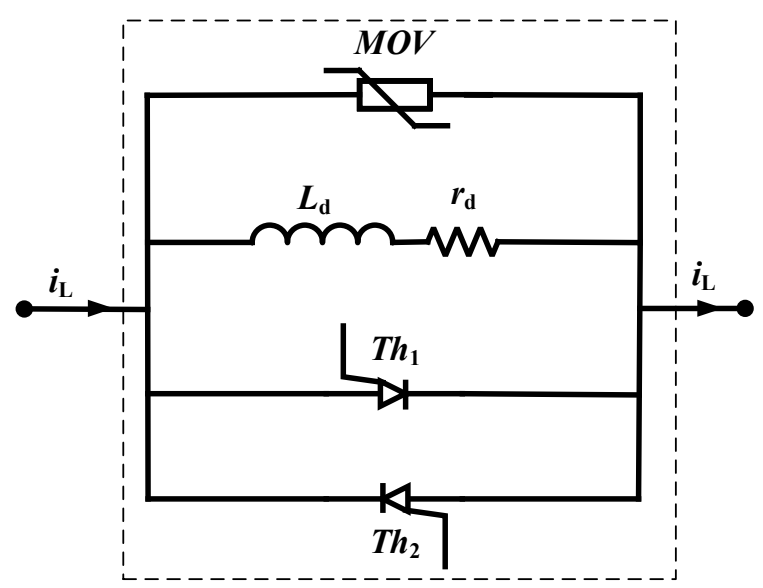

Fig. 2. Proposed TCAR topology mode, the antiparallel switches are in ON state for positive and negative half cycles of the line current. In this case, the series AC reactor is bypassed via these switches and there is no voltage drop on it. In the instant of fault inception, the control system detects the fault current and turns the thyristors off at zero current. In this case, the fault current flows form the series $\mathrm{AC}$ reactor and its impedance decreases the fault current to an acceptable level.

The paralleled MOV is used to decrease the switching overvoltage in the instant of fault inception and fault removal. The advantages of the proposed FCL are negligible power losses during normal operation, fast operation in the instant of fault occurrence, acceptable power quality, simple structure and cost-effective FCL.

\subsection{Circuit analysis}

According to the value of feeder current, TCAR operates in two modes. In normal operation mode, when the system operates at steady state, thyristors are in on state and there is negligible voltage drop on TCAR. The other mode corresponds to the fault condition, when the feeder current exceeds $I_{\mathrm{L}}$. In this mode thyristors are in off state and the fault current is limited by the $\mathrm{AC}$ reactor. During the normal mode, $\mathrm{AC}$ reactor current is zero and the line current is given by Eq. (1).

$$
V_{m} \sin (\omega t)=L \frac{d i_{L}(t)}{d t}+R i_{L}(t)
$$

where, $R$ and $L$ include the source, line, and load resistances and inductances and the source voltage of the electrical network is assumed sinusoidal. In this case the system is in steady state, i.e. the transient component of current has already been damped. Therefore, the solution of Eq. (1) is as given in Eq. (2).

$$
i_{L}(t)=\frac{V_{m}}{\sqrt{R^{2}+\omega^{2} L^{2}}} \sin \left(\omega t-\tan ^{-1} \frac{\omega L}{R}\right)
$$

In fault condition, the line current increases rapidly and 


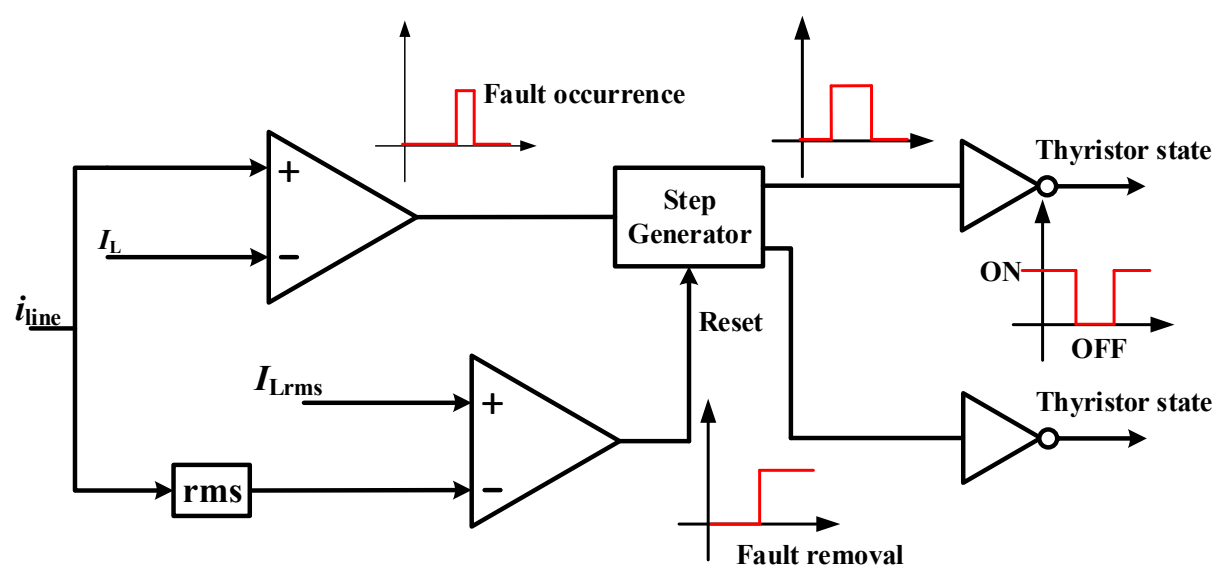

Fig. 3. Control logic block diagram of TCAR

exceeds $I_{\mathrm{L}}$, by which the controller turns-off the antiparallel thyristors and connects the $\mathrm{AC}$ reactor to the feeder. During fault mode, the AC reactor charges according to Eq. (1), but with the values of $L$ and $R$ including TCAR inductance and resistance and excluding the short circuited load parameters. Solving equation (1) for the fault condition yields:

$$
i_{L}(\omega t)=A e^{-\frac{R}{L \omega} \omega\left(t-t_{1}\right)}+B \sin (\omega t-\varphi)
$$

where,

$$
A=\frac{-V_{m}}{\sqrt{R^{2}+\omega^{2} L^{2}}}, B=\frac{V_{m}}{\sqrt{R^{2}+\omega^{2} L^{2}}}, \varphi=\arctan \left(\frac{\omega L}{R}\right)
$$

Eq. (3) is composed of exponential and sinusoidal terms. The exponential term causes a transient in the line current, duration of which (from $t_{1}$ to $t_{2}$ ) depends on the system time constant $\left(L_{\mathrm{d}} / R\right)$, where $R$ is the system resistance seen by the $\mathrm{AC}$ reactor.

\section{Control Strategy of the Proposed TCAR}

The TCAR operation needs the control circuit. The control block diagram of the proposed TCAR is shown in Fig. 3. In the normal mode, the thyristors are $\mathrm{ON}$ and the line current passes through these switches. So, the AC reactor is bypassed and TCAR behaves as a short-circuit equipment. At fault inception, the line current increases and becomes greater than the maximum permissible current $\left(I_{\mathrm{L}}\right)$ and the control circuit turns the thyristors off.

After fault removal, the line current will be instantaneously decreased. To detect this line current reduction, $i_{\mathrm{L}}$ is passed from Root Mean Square (RMS) block and is compared with $I_{\text {Lrms. }}$. When the differences of these two currents become greater than the threshold level $(k)$, the control circuit changes the TCAR topology from
Table 1. Distribution network parameters

\begin{tabular}{c|c|c}
\hline Parameters & description & value \\
\hline$V_{\mathrm{s}}($ experimental $)$ & Source Voltage (Line-ground) rms & $110 \mathrm{~V}$ \\
\hline$V_{\mathrm{s}}($ Simulation) & Source Voltage (Line-Line) rms & $20 \mathrm{kV}$ \\
\hline$r_{\mathrm{s}}$ & Source Resistance & $1 \Omega$ \\
\hline$L_{\mathrm{s}}$ & Source Inductance & $0.01 \mathrm{H}$ \\
\hline$r_{\mathrm{L}}$ & Line Resistance & $1 \Omega$ \\
\hline$L_{\mathrm{L}}$ & Line Inductance & $0.01 \mathrm{H}$ \\
\hline$f$ & Power System Frequency & $50 \mathrm{~Hz}$ \\
\hline$V_{\mathrm{Th}}$ & Voltage Drop Across Thyristors & $2 \mathrm{~V}$ \\
\hline$r_{\mathrm{d}}$ & AC Reactor Resistance & $0.02 \Omega$ \\
\hline$L_{\mathrm{d}}$ & AC Reactor Inductance & $0.1 \mathrm{H}$ \\
\hline$R_{\text {load }}$ & Load Resistance & $96.8 \Omega$ \\
\hline$L_{\text {load }}$ & Load Inductance & $0.1 \mathrm{H}$ \\
\hline \multicolumn{2}{|}{}
\end{tabular}

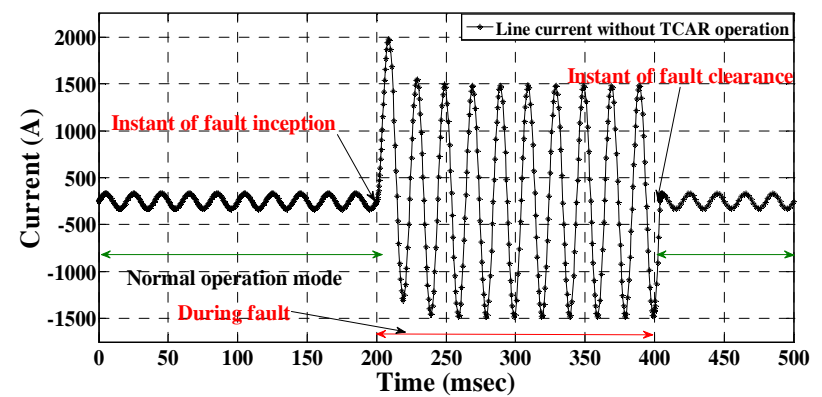

Fig. 4. Line current during normal and fault operation modes without FCL effect

the fault mode to the invisible mode. So, the network returns to the normal state.

\section{Simulation Results}

In this section, the distribution network of Fig. 1 is simulated via MATLAB Simulink and the results are given here. In Table (1) the parameters values of the proposed network and TCAR are listed.

Fig. 4 shows the line current during normal and fault operation modes. During normal mode, the line current is 
sinusoidal and system works under normal condition. In $t=200 \mathrm{~ms}$ the fault is occurred and the line current is increased rapidly while first peak of the fault current is reached to $2 \mathrm{kA}$.

In this case there is no connected TCAR in the line and the fault current can fail the network equipments. Fig. 5 shows the line current during normal and fault operation modes while the proposed TCAR is connected in series with the feeder.

In this case, the normal current is the same as the previous case but in the instant of fault inception the TCAR is operated and decreased the fault current to an acceptable level with $600 \mathrm{~A}$ current amplitude. The fault is cleared at $t=400 \mathrm{~ms}$ and the controller detects the fault removal instant but it turns-on the anti-parallel thyristors after $10 \mathrm{~ms}$ delay. During this delay, both electrical load and series AC reactor are connected to the network that decreases the line current and discharges the stored energy of the series $\mathrm{AC}$ reactor. At $t=410 \mathrm{~ms}$ the antiparallel thyristors bypass the series reactor and return the distribution network to the pre-fault condition.

Fig. 6 shows the electrical load voltage during normal and fault. The load voltage has a good quality during the normal mode but solid fault decreases the load voltage to zero. After fault removal, the TCAR is bypassed after $10 \mathrm{~ms}$ delay and during this half cycle the load voltage is decreases. After that, the load voltage returns to the prefault value and feeds the load. During the fault period, the Point of Common Coupling (PCC) voltage decreases and the magnitude of the voltage sag is increased due to the

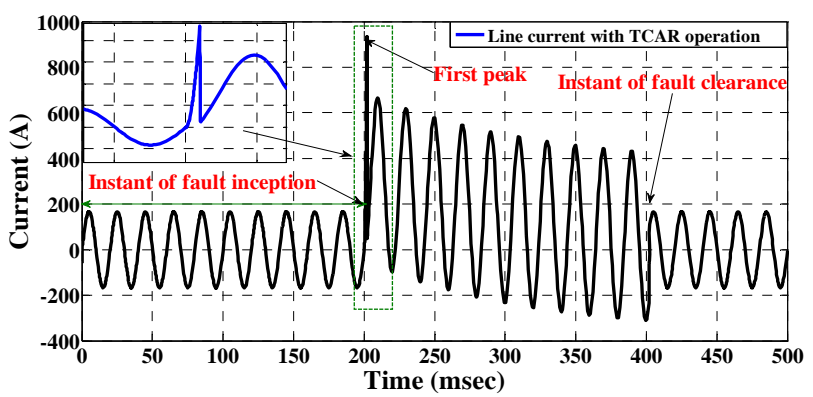

Fig. 5. Line current during normal and fault operation modes affected by TCAR



Fig. 6. Load voltage during normal and fault operation modes affected by TCAR

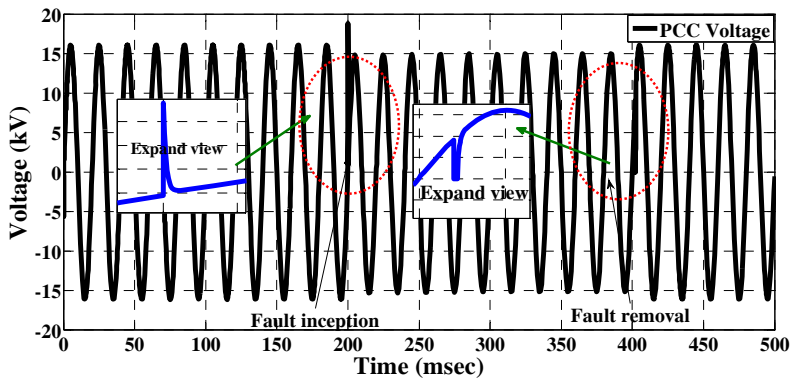

Fig. 7. PCC voltage during normal and fault operation modes affected by TCAR

type of the short circuit fault. The solid ground fault can cause severe voltage sag. In this case, the FCL injects the considerable impedance to the line, decreases the fault current and restores the PCC voltage to an acceptable level. Fig. 7 shows the PCC voltage during the normal and fault operation modes. The switching effect on the PCC voltage in the instant of fault inception and removal is clearly obvious as shown with expands view on this figure.

\section{Experimental Results}

The scale-down laboratory prototype of the TCAR is built based on Fig. 2. This prototype is tested under $110 \mathrm{Vrms}$ voltage level and the experimental results are given in this section. Fig. 8 shows the measured line current during normal and fault operation modes while there is no connected TCAR in the line. Fig. 9 shows the TCAR effect on the line current and load voltage. This figure includes two channels of the digital oscilloscope where channel 1 shows the load voltage and channel 2 illustrates the line current, both waveforms show the normal, fault and post fault conditions.

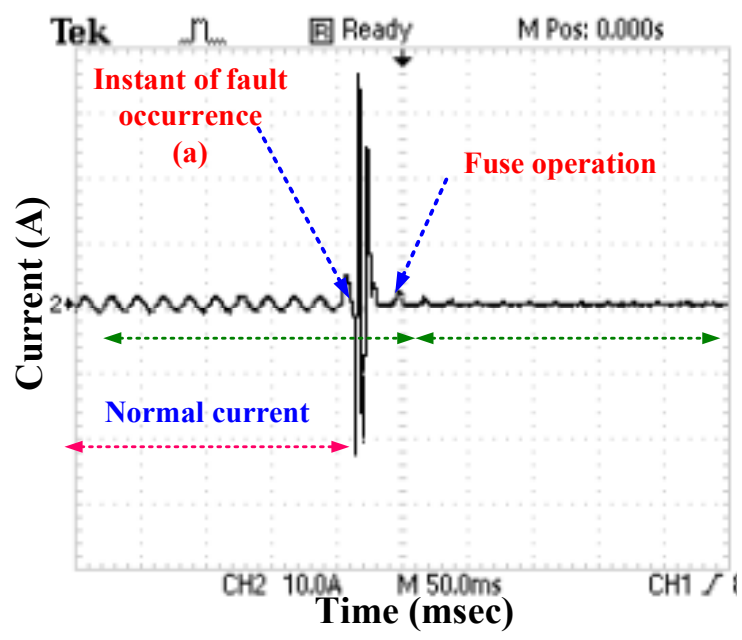

Fig. 8. Line current during the normal and fault operation modes without TCAR operation ((probe of channel 2 is $\mathrm{X} 1$ ) 


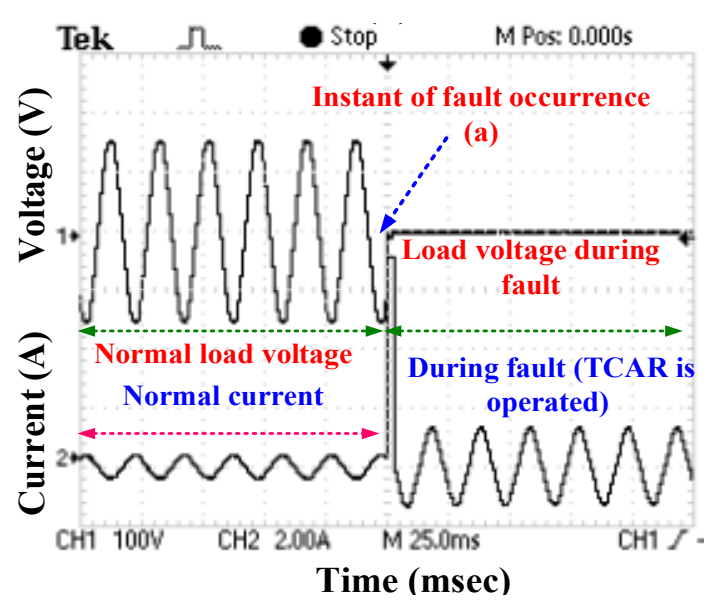

(a)

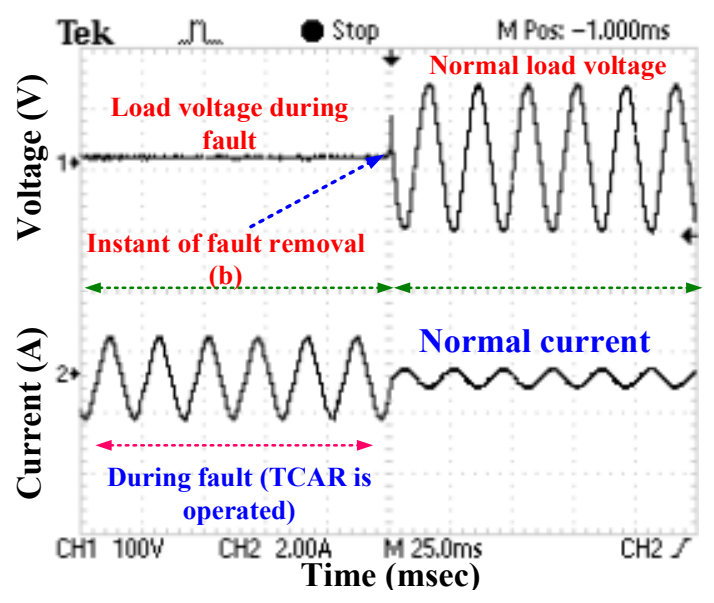

(a)

Fig. 9. Load voltage (upper waveform in channel 1) and line current (lower waveform in channel 2) during normal and fault operation modes (probe of channel 1 is $\mathrm{X} 1$ and probe of channel 2 is X3) a) instant of fault inception and b) instant of fault removal

The lower waveform of Fig. 9 is in good agreement with Fig. 5 and the upper waveform is in agreement with Fig. 6. Fig. 10 shows PCC voltage and AC reactor current of the proposed network during normal and fault modes. During fault, the TCAR is restored the PCC voltage to an acceptable level but there is little voltage sag during the fault period. The upper waveform of this figure is in good agreement with Fig. 7.

\section{Comparative Study}

Fig. 11 shows the typical topology of an FCL with discharging capacitors [13]. This FCL includes two discharging capacitors $C_{1}$ and $C_{2}$, two main thyristors $T h_{1}$ and $T h_{2}$, two auxiliary thyristors $T h_{1 \mathrm{~A}}$ and $T h_{2 \mathrm{~A}}$, two limiting impedances $R_{1}$ and $R_{2}$, two rectifier diodes and two AC reactors $L_{1}$ and $L_{2}$. The main thyristors are used to conduct the line current during normal operation mode. At

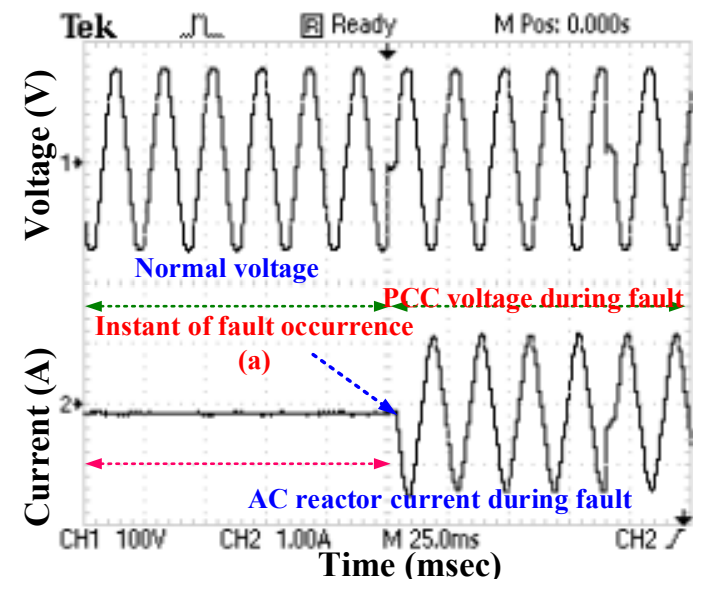

(a)

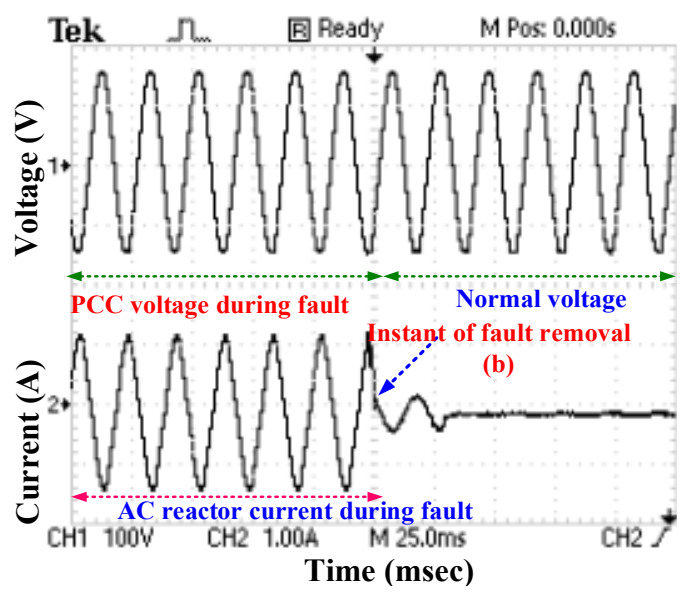

(b)

Fig. 10. PCC voltage (upper waveform in channel 1) and AC reactor current (lower waveform in channel 2) during normal and fault operation modes (probe of channel 1 is X1 and probe of channel 2 is X2) a) instant of fault inception and b) instant of fault removal

fault inception, the main thyristors could turned off at the next natural zero-crossing of the line current. To overcome the thyristors delay, an artificial (induced) zero-crossing of the current through the main thyristors is obtained by triggering the auxiliary thyristors and discharging the precharged capacitors $C_{1}$ and $C_{2}$ [13].

In this case, the fault current is delivered to the $R_{1}$ and $R_{2}$ and limited by these resistors [13]. This FCLs employs two auxiliary thyristors and discharging capacitor to insert the resistive impedance during the fault period. The magnitude of the follow current to each branch can be controlled by adjusting the phase angle of the main thyristors. However, this FCL has a considerable power losses on the equipments, it is not cost effective due to its components, it needs costly cooling system and complicated control system. But the suggested TCAR has a simple structure, the power losses on its components are negligible and it has a simple control 


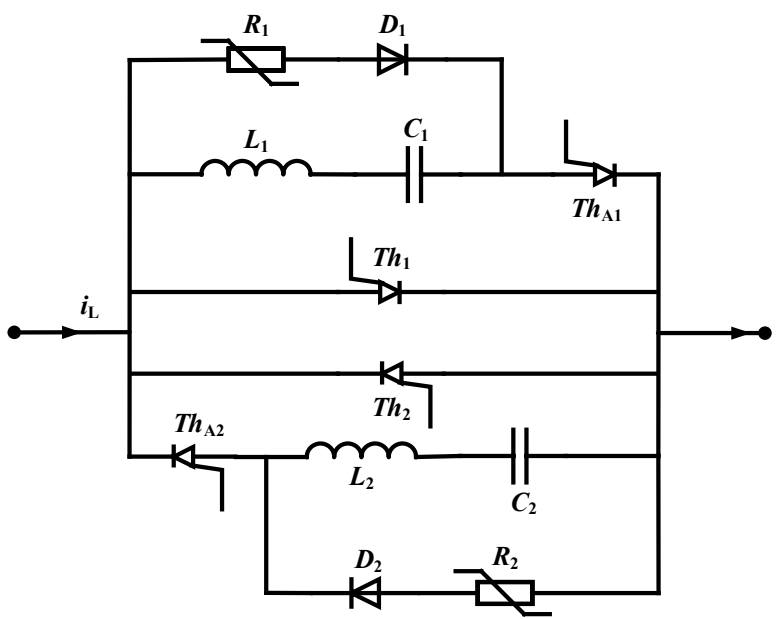

Fig. 11. Typical topology of an FCL with discharging capacitors

system [13-15]. Development of the proposed single-phase TCAR to three-phase TCAR is easy. The three-phase version consists of three similar single-phase structures of the TCAR and they can independently operate in each phase of the network. A point that should especially be noted is that fewer components are required for the proposed TCAR as compared with other FCLs [13-15]. According to the simulation and experimental results, it has been proved that the proposed TCAR is effective for fault current breaking and restoring the PCC voltage to the acceptable level. For high-voltage applications, the insulation levels of the reactor, Thyristors protection and proper cooling system need to be properly taken into account.

\section{Conclusion}

This paper employs a modified version of ThyristorControlled AC Reactor (TCAR) for fault current limitation proposes. The suggested TCAR has a simple and costeffective structure and can control the fault current successfully. The on-state power losses of the TCAR are relatively low and its speed of operation is fast. The switching overvoltage of the TCAR is clamped by using MOV in parallel with the switches. The series reactor of the TCAR is bypassed during the normal operation mode and the TCAR shows negligible impedance during this mode. Furthermore, the inductance value of the series reactor can increase according to the network requirement without increasing the TCAR losses. This TCAR is suitable for distribution network application and it can improve the system stability and reliability.

\section{References}

[1] Dewadasa, M., Ghosh, A., Ledwich, G., Wishart, M.:
'Fault isolation in distributed generation connected distribution networks', IEE Proceedings Generation, Transmission and Distribution, vol. 5, no. 10, pp. 1053-1063, 2011.

[2] Bae Na, J., Jae Kim, Y., Young Jang, J., et al.: 'Design and tests of prototype hybrid superconducting fault current limiter with fast switch', IEEE Transactions on Applied Superconductivity, vol. 22, no. 3, pp. 5602604-5602604, 2012.

[3] Tseng, S.-T.; Chen, J.-F., "Capacitor energising transient limiter for mitigating capacitor switch-on transients," IET Electric Power Applications, vol. 5, no. 3, pp. 260-266, March 2011.

[4] Seyed Majid Madani, Mehrdad Rostami, G.B. Gharehpetian, Reza Hagh Maram, Improved bridge type inrush current limiter for primary grounded transformers, Electric Power Systems Research, vol. 95, Pages 1-8, February 2013.

[5] Hsu-Ting Tseng; Jiann-Fuh Chen, "Single-DC ReactorType Transient Limiter for Reducing Three-Phase Power Capacitor Switching Transients," IEEE Transactions on Power Electronics, vol. 27, no. 4, pp.1745-1757, April 2012.

[6] Abramovitz, A., Smedley, K.M.: 'Survey of solidstate fault current limiters', IEEE Transactions on Power Electronics, vol. 27, no. 6, pp. 2770-2782, 2012.

[7] Boenig, H.J., Paice, D.A.: 'Fault current limiter using a superconducting coil', IEEE Transactions on Magnetics, vol. 19, no. 3, pp. 1051-1053, 1983.

[8] Lu, Z., Jiang, D., Wu, Z.: 'A new topology of faultcurrent limiter and its parameters optimization'. Proc. IEEE Power Electronics Specialist Conf., pp. 462465, 2003.

[9] Seyed Behzad Naderi, Mehdi Jafari, Mehrdad Tarafdar Hagh, Controllable resistive type fault current limiter (CR-FCL) with frequency and pulse duty-cycle, International Journal of Electrical Power \& Energy Systems, vol. 61, Pages 11-19, October 2014.

[10] Firouzi, M.; Gharehpetian, G. B., "Improving Fault Ride-Through Capability of Fixed-Speed Wind Turbine by Using Bridge-Type Fault Current Limiter," IEEE Transactions on Energy Conversion, vol. 28, no. 2, pp. 361-369, June 2013.

[11] Hagh, M. T.; Abapour, M., "Nonsuperconducting Fault Current Limiter with Controlling the Magnitudes of Fault Currents," IEEE Transactions on Power Electronics, vol. 24, no. 3, pp. 613-619, March 2009.

[12] Nomura, T., Yamaguchi, M., Fukui, S., Yokoyama, K., Satoh, T., Usui, K.: 'Single DC reactor type fault current limiter for $6.6 \mathrm{kV}$ power system', IEEE Transactions on Applied Superconductivity, vol. 11, no. 1, pp. 2090-2093, 2001.

[13] Mathias Noe and Michael Steurer, "High-temperature 
superconductor fault current limiters: concepts, applications, and development status", Superconductor Science and Technology, vol. 20, no. 3, 2007.

[14] R. K. Smith, "Solid-state distribution current limiter and circuit breaker: application requirements and control strategies", IEEE Transactions on Power Delivery, Vol. 8, No. 3, July 1993.

[15] T. Ueda, "Solid-state current limiter for power distribution system", IEEE Transactions on Power Delivery, Vol. 8, No. 4, October 1993.

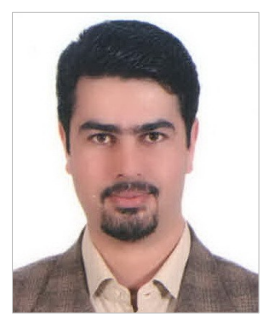

Hamid Radmanesh was born in 1981. He received his B.Sc., M.Sc. and Ph.D. degrees in electrical engineering in 2006, 2009 and 2015 from MalekAshtar University of Technology, Tehran, Iran, Shahed University, Tehran, Iran and Amirkabir University of Technology (AUT), Tehran, Iran, respectively. Currently, he is an Assistant Professor of electrical engineering department at aeronautical university of science\& technology. He teaches high voltage insulation technology, transient in power system and apparatus. He is the author of more than 50 journal and conference papers. His research interests include design and modeling of power electronic converters, FCLs, drives, and transient in power system, chaos in power system apparatus.



Seyed Hamid Fathi received the B.Sc. degree in electrical engineering from the Amirkabir University of Technology (AUT), Tehran, Iran, in 1984, the M.Sc. degree in electrical engineering from the Iran University of Science and Technology, Tehran, in 1987, and the Ph.D. degree in electrical engineering from the University of Newcastle upon Tyne, Newcastle Upon Tyne, U.K., in 1991. Afterward, he joined AUT, where he is currently an Associate Professor with the Department of Electrical Engineering. His research interests include power quality, flexible ac transmission systems, power electronics, and electric drives.

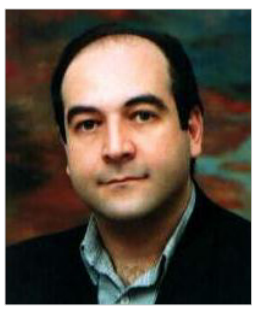

G. B. Gharehpetian received his BS, MS and Ph.D. degrees in electrical engineering in 1987, 1989 and 1996 from Tabriz University, Tabriz, Iran and Amirkabir University of Technology (AUT), Tehran, Iran and Tehran University, Tehran, Iran, respectively, graduating all with First Class Honors.

He has been holding the Assistant Professor position at AUT from 1997 to 2003, the position of Associate Professor from 2004 to 2007 and has been Professor since 2007. He is the author of more than 700 journal and conference papers. His teaching and research interest include Smart Grid, DGs, Monitoring of Power Transformers, FACTS Devices, HVDC Systems and Power System Transients. 